\title{
Determinants of the Motoric Subtypes of Delirium in Elderly
}

\author{
Hamza SA ${ }^{1}$, Ali SH ${ }^{1}$, El-Mashad NB ${ }^{2}$, and El-sobki $\mathrm{HS}^{3}$ \\ 1 Geriatrics and Gerontology Department, Faculty of Medicine, Ain Shams University, Cairo, Egypt. \\ 2Clinical Ppathology Department, Faculty of Medicine, Mansoura University, Dakahlia, Egypt. \\ 3 Geriatrics and Gerontology Department, Faculty of Medicine, Mansoura University, Dakahlia, Egypt. \\ Correspondence: fersanarabia@gmail.com
}

\begin{abstract}
Background: Several studies have confirmed the existence of three clinical forms for delirium: hyperactive, hypoactive, and mixed, based on psychomotor behavior

Aim: study the association between the psychomotor activity among different delirium subtypes and the admission characters in delirious elderly patients to prove a hypothesis that hypoactive delirium carries worse underlying admission characters.
\end{abstract}

Methods: A cross-sectional study was conducted on 45 newly admitted delirious elderly diagnosed with "Confusion Assessment Method" CAM. Psychomotor activity was detected. Assessment of baseline depression, function by Activities of daily living ( $A D L)$, Instrumental activities of daily living (IADL), APACHE score and Erythrocyte sedimentation rate (ESR) were done.

Results: Mean age was $71.2 \pm 7.9$ years (range 60.0-91.0). 27 (60\%) of patients were females. According to psychomotor characteristics, $19(42.2 \%)$ of the participants were hypoactive, $13(28.9 \%)$ were hyperactive and 13 $(28.9 \%)$ were mixed. Unlike the hyperactive groups; the hypoactive and mixed group have significantly high ESR. There was no significant association between motoric subtypes and presence of premorbid depression or functional dependence. There was no significant difference in baseline comorbidities among the three subtypes. Regarding the underlying etiology, Hypoglycemia was significantly most frequent among hypoactive patients while dehydration was significantly most frequent among patients with mixed type. APACHE score and the calculated mortality score were highest in hypoactive subtype and least among hyperactive, yet, this was of no statistical significance.

Conclusions: The hypoactive form of delirium is common among older persons. Inflammation has a role in the pathology of hypoactive delirium as indicated by high ESR. It is recommended to promptly recognize hypoactive delirium and to put a proper plan for ADL support and functional rehabilitation.

Keywords: delirium subtypes- hypoactive- function- elderly- mortality

\section{Background}

Delirium is a common neuropsychiatric syndrome encountered in all hospital settings and is usually associated with many deleterious effects. Patients with delirium tend to require longer hospital stays and have higher mortality rates, even when the severity of their underlying illness is accounted for ${ }^{(1,2)}$. Hospitalized patients with delirium are known to exhibit different symptoms ranging from lethargy and inattentiveness to restlessness, watchful, and combative behavior ${ }^{(3,4)}$. Based on systematic clinical observation of hospitalized patients, the spectrum of psychomotor behavior seen in delirious patients can be classified as hyperactive, hypoactive or mixed-type ${ }^{(4,5)}$.

It has been suggested that each delirium subtype can result from a different pathophysiological mechanism, 
and that each might carry a different prognosis (6). Moreover, the existence of different subtypes has been shown to affect the detection of delirium ${ }^{(7)}$. For example, in non-ICU patients, hyperactive delirium is readily recognized in the course of routine clinical care and is associated with lower mortality than hypoactive or mixed-type delirium ${ }^{(7)}$.

Hypoactive delirium, also referred to as "quiet delirium," is often unrecognized or misdiagnosed as sedation or depression ${ }^{(8)}$. Early identification and timely management are the keys to reduce the early complications and long-term sequelae of delirium in hospitalized elderly ${ }^{(9)}$. Our hypothesis is that hypoactive delirium carries worse underlying admission characters. In this study, the relationship between motoric subtypes of delirium and admission characters of the 45 newly admitted delirious elderly patients was investigated in order to better understand delirium.

\section{Methods \\ Study design}

A cross-sectional study was conducted in the general medical ward in Al-Mansoura Teaching Hospital in Dhakahlia governorate. 45 consecutive patients were recruited over a 6-month period. Investigators prospectively collected data on every patient who met inclusion criteria. Eligible patients in this study were $\geq$ 60 years old and were admitted directly from an acutecare medical or surgical hospitalization. Only baseline assessments were used in this study. Birth date, sex, race, comorbidities and Acute Physiology and Chronic Health Evaluation II (APACHE II) score ${ }^{(10)}$ were assessed.

\section{Delirium Assessment}

The Confusion Assessment Method (CAM) is a diagnostic algorithm derived from Diagnostic and Statistical Manual of Mental Disorders, Third Revision (DSM-III-R) criteria for delirium. The CAM allows trained research assistants to perform ratings of delirium presence that agree with a psychiatrist's diagnosis with greater than $95 \%$ sensitivity and specificity, even in populations with a high prevalence of dementia (11). The CAM diagnostic algorithm involves four criteria: 1) an acute change in mental status with a fluctuating course, 2) inattention, 3) disorganized thinking, and 4) an altered level of consciousness ${ }^{(11)}$. Delirium was considered present if CAM criteria 1 and 2 were present, and either criteria 3 or 4 were present.

\section{Delirium motoric subtypes:}

Patients were later subdivided into delirium subtypes by group consensus, using all available data from a review of case records and the information from the consultation. The psychomotor subtypes used were initially described by Liptzin and Levkoff ${ }^{(12) .}$ Cases were classified into hyperactive, hypoactive, and mixed subtypes according to the presence or absence of defined symptoms.

Since these delirium groups are primarily defined according to motor activity levels, they will be referred to as motoric subtypes.

\section{Assessment:}

Laboratory data includes; Erythrocyte sedimentation rate (ESR) was considered to be markers of inflammatory activity. ESR $(\mathrm{mm} / \mathrm{h})$ was measured by the Westegren method.

Assessment of depression is done by Cornell scale. Cornell scale is used if patient is unable to communicate. The Cornell Scale for Depression in Dementia (CSDD) is designed for the assessment of depression in older people with dementia who can at least communicate basic needs ${ }^{(13)}$.

Assessment of function is done by activities of daily living (ADL) and instrumental activities of daily living (IADL).Activities of daily living (ADLs) are basic activities that include bathing, dressing, toileting, transfer, continence, and feeding (14). Persons are limited in an ADL if they are unable to perform the activity, use active help, use equipment, or require standby help ${ }^{(14)}$. ADL included questions that assessed the person's ability to perform the activity independently, the extent of difficulty with the activity, available assistance, and need for assistance associated with the activity.

Instrumental activities of daily living (IADLs) are indicators of more complex tasks such as the ability to do housework (e.g., dusting, washing dishes, laundry), do heavy cleaning or yard work, use the telephone, get outdoors, shop, prepare one's own meals, take medications, and manage money ${ }^{(15)}$. Persons may be limited in an IADL activity if they cannot do the activity because of a disability, health problem, or environmental barrier. Items used on IADL scales vary ${ }^{(15)}$. It included eight items assessing IADLs. Both ADL and IADL questions have been tested with various rating formats and scoring procedures and have acceptable levels of reliability and validity for use in surveys ${ }^{(16,17)}$.

\section{Ethical considerations:}

The procedures and rationale for the study were explained to all patients; however, because patients were delirious at study entry, it was presumed that most were incapable of giving informed written consent. Family caregivers provided informed consent using a protocol approved by the local ethics committee. 


\section{Statistical Methods}

The collected data were coded, tabulated, and statistically analyzed using IBM SPSS statistics (Statistical Package for Social Sciences) software version 22.0, IBM Corp., Chicago, USA, 2013. Descriptive statistics were done for quantitative data as minimum\& maximum of the range as well as mean $\pm \mathrm{SD}$ (standard deviation) for quantitative parametric data, while it was done for qualitative data as number and percentage. Inferential analyses were done for quantitative variables using independent t-test in cases of two independent groups with parametric data and Chi square test for differences between proportions. Logistic regression model was used to find out independent factors affecting delirium. The level of significance was taken at $\mathrm{P}$ value $<0.05$ is significant.

\section{Results}

\section{Baseline Characteristics}

The mean age of the 45 delirious patients was 71.2 \pm 7.9 years (range 60.0-91.0), 27 patients (60\%) were female. Classification according to motoric subtypes revealed that $19(42.2 \%)$ were hypoactive, $13(28.9 \%)$ were hyperactive, and $13(28.9 \%)$ were mixed. There were no significant age differences among the different motoric subtypes $(\mathrm{P}=0.697)$.

There was no significant difference between the different motoric subtypes regarding comorbidities (figure 1). The most likely primary etiologies for delirium are represented in Table1. Hypoglycemia was the most frequent etiology among the hypoactive group $(\mathrm{P}=0.014)$, while dehydration was the most frequent one among the mixed type group $(\mathrm{P}=0.012)$. The ESR was significantly highest among mixed group and least among hyperactive group $(\mathrm{P}=0.008)$. The APACHE score and its calculated mortality score were highest in hypoactive subtype and least among hyperactive, yet, this was of no statistical significance $(\mathrm{P}<0.05)$ (Table 2).

Table (3) shows that hypoactive group tends to have higher depression score and are more dependent concerning ADL and IADL function scales but these results did not reach statistical significance $(\mathrm{P}<0.05)$.

\section{Discussion}

Delirium is traditionally classified according to psychomotor behavior into three subtypes: hyperactive, hypoactive and mixed delirium ${ }^{(17)}$. The two most common types of delirium in the ICU are mixed and hypoactive types ${ }^{(18)}$. Hypoactive delirium tends to occur more frequently in older patients compared to other types of delirium and it has a worse prognosis ${ }^{(19)}$. In the current study, age didn't differ across different subtypes. This may be due to small sample size. In this sample, hypoactive delirium was more common representing $(42.2 \%)$ while each of mixed and hyperactive types occurred in $(28.9 \%)$ of the participants. Results were variable as regard the prevalent subtype of delirium. In Robinson and his colleagues study, 2011, hypoactive represented $68 \%$, while mixed and hyperactive represented $31 \%, 1 \%$ respectively ${ }^{(19)}$. Other studies revealed that mixed delirium was more common ${ }^{(12)}$.

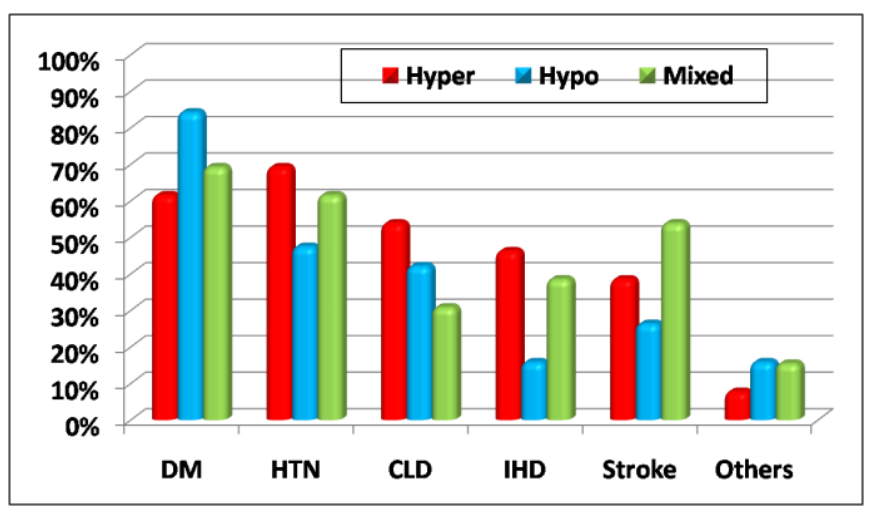

Fia 1 There is no sianificant difference between subtvpes of

Table (1): Causes of admission condition among subtypes of delirium.

\begin{tabular}{|l|c|c|c|c|}
\hline Variables & $\begin{array}{c}\text { Hyperactive } \\
(\mathrm{N}=13)\end{array}$ & $\begin{array}{c}\text { Hypoactive } \\
(\mathrm{N}=19)\end{array}$ & $\begin{array}{c}\text { Mixed } \\
(\mathrm{N}=13)\end{array}$ & $\mathbf{P}$ \\
\hline Hypoglycemia & $0(0.0 \%) \mathrm{a}$ & $6(31.6 \%) \mathrm{b}$ & $\begin{array}{c}0 \\
(0.0 \%) \mathrm{a}\end{array}$ & $\# 0.014^{*}$ \\
\hline $\begin{array}{l}\text { Uncontrolled } \\
\text { HTN }\end{array}$ & $0(0.0 \%)$ & $0(0.0 \%)$ & $1(7.7 \%)$ & $\# 0.578$ \\
\hline Dehydration & $0(0.0 \%) \mathrm{a}$ & $5(26.3 \%) \mathrm{b}$ & 6 & $\# 0.012^{*}$ \\
\hline $\begin{array}{l}\text { Stroke } \\
\text { Hepatic }\end{array}$ & $4(30.8 \%)$ & $1(5.3 \%)$ & $\begin{array}{c}2 \\
(15.4 \%)\end{array}$ & $\# 0.174$ \\
\hline $\begin{array}{l}\text { Encephalopathy } \\
\text { encephalonsive }\end{array}$ & $4(30.8 \%)$ & $1(5.3 \%)$ & $1(7.7 \%)$ & $\# 0.551$ \\
\hline $\begin{array}{l}\text { Hyperosmolar } \\
\text { Hyperglycemic } \\
\text { State }\end{array}$ & $2(15.4 \%)$ & $4(21.1 \%)$ & $1(7.7 \%)$ & $\# 0.870$ \\
\hline
\end{tabular}

\#Fishers Exact test, "Significant, Symbols a, b, c: homogenous groups have the same symbol in the post hoc Fisher Exact tests.

Hypoglycemia was significantly most frequent among hypoactive type. Dehydration was significantly most frequent among mixed type. 
Table (2): The admission characteristics among the different subtypes of delirium

\begin{tabular}{|c|c|c|c|c|c|}
\hline \multicolumn{2}{|c|}{ Variables } & $\begin{array}{l}\text { Hyperactive } \\
(\mathrm{N}=13)\end{array}$ & $\begin{array}{l}\text { Hypoactive } \\
(\mathrm{N}=19)\end{array}$ & $\begin{array}{l}\text { Mixed } \\
(N=13)\end{array}$ & $\mathbf{P}$ \\
\hline \multirow[t]{2}{*}{ APACHE } & Mean $\pm S D$ & $14.6 \pm 4.3$ & $18.1 \pm 5.4$ & $15.7 \pm 7.4$ & \multirow[t]{2}{*}{$=0.23$} \\
\hline & Range & $6.0-21.0$ & $11.0-28.0$ & $7.0-32.0$ & \\
\hline \multirow{2}{*}{$\begin{array}{l}\text { Mortality } \\
\text { risk }\end{array}$} & Mean $\pm S D$ & $20.5 \pm 10.3$ & $29.1 \pm 13.1$ & $24.6 \pm 20.1$ & \multirow[t]{2}{*}{$=0.28$} \\
\hline & Range & $8.0-40.0$ & $15.0-55.0$ & $4.0-73.0$ & \\
\hline \multirow[t]{2}{*}{$\begin{array}{l}\text { ESR } \\
(\mathrm{Mm} / \mathrm{hr} .)\end{array}$} & Mean $\pm S D$ & $12.2 \pm 16.1 \mathrm{a}$ & $41.5 \pm 42.3 b$ & $\begin{array}{l}56.9 \pm 38.0 \\
b\end{array}$ & \multirow[t]{2}{*}{$0.008^{*}$} \\
\hline & Range & $4.0-65.0$ & $5.0-120.0$ & $6.0-110.0$ & \\
\hline
\end{tabular}

Table (3): Depression, ADL and IADL before admission among different subtypes of delirium.

\begin{tabular}{|l|l|l|l|l|l|}
\hline \multicolumn{2}{|c|}{ Variables } & $\begin{array}{l}\text { Hyperactive } \\
(\mathrm{N}=13)\end{array}$ & $\begin{array}{l}\text { Hypoactive } \\
(\mathrm{N}=19)\end{array}$ & $\begin{array}{l}\text { Mixed } \\
(\mathrm{N}=13)\end{array}$ & \#P \\
\hline Depression & $8(61.5 \%)$ & $13(68.4 \%)$ & $11(84.6 \%)$ & $\& 0.41$ \\
\hline \multirow{2}{*}{ ADL } & Dependent & $5(38.5 \%)$ & $10(52.6 \%)$ & $9(69.2 \%)$ & $\# 0.29$ \\
\cline { 2 - 6 } & Independent & $8(61.5 \%)$ & $9(47.4 \%)$ & $4(30.8 \%)$ & \\
\hline IADL & Dependent & $5(38.5 \%)$ & $10(52.6 \%)$ & $9(69.2 \%)$ & \\
\cline { 2 - 5 } & Independent & $8(61.5 \%)$ & $9(47.4 \%)$ & $4(30.8 \%)$ & \\
\hline
\end{tabular}

^ANOVA test, \#Fishers Exact test, *Significant, Symbols a, b, c: homogenous groups are the same symbol in the post hoc Fisher Exact tests.

ESR was significantly highest among mixed group and least among hyperactive group.
For example, Peterson and his colleagues, 2006 showed that mixed type was the most common variant (54.9\%), followed by hypoactive delirium $(43.5 \%)$ and lastly the purely hyperactive delirium (1.6\%) (18). However, other studies revealed that hyperactive delirium was more common. Mushtaq and his colleagues, 2014, showed that $70 \%$ of cases were hyperactive delirium (20). In Grover and his colleagues, 2014 study $50 \%$ of cases were hyperactive while each of the other two types represented $25 \%$ (21). A study done by Aly and his colleagues, 2013 included 58 delirious 46 were hyperactive, 2 hypoactive and 10 mixed (22).

The difference between studies can be explained by variation in age group of the studied populations as hypoactive delirium was seen more commonly in older age (19) and hyperactive was more common at younger age (23). It can be also explained by different etiology. The hyperactive subtype was often associated with medication side effects and drug withdrawal (24) while metabolic abnormalities such as hepatic toxicity and dehydration were more often associated with the hypoactive subtype (25).

The current study showed that there was no significant difference between subtypes of delirium regarding comorbidities. This may be due to relatively small sample size, so it was hard to identify significant difference between types of delirium. Several studies have suggested that delirium types may differ according to etiology, pathophysiology, detection rates, delirium treatment experience and duration of episodes and outcome $(27,29)$.

The current results showed that hypoglycemia was significantly more frequent among hypoactive type and dehydration was significantly more frequent among mixed type. As stated before, Solai and his colleagues found that metabolic abnormalities were more often associated with the hypoactive subtype (27). On the contrary, cerebrovascular disorders were associated with hypoactive delirium development in a large study in internal medicine wards in which a high prevalence $(65 \%)$ of hypoactive delirium was recorded (28).

In the current study, ESR was significantly higher among mixed then hypoactive group and least among hyperactive group. As mentioned, underlying cause of hyperactive is usually associated with drug side effects which will not lead to much rise in ESR. On the contrary, mixed type in this study is caused by dehydration and hypoactive type 
by hypoglycemia, both etiologies lead to metabolic derangements which leads to a rise in ESR.

There was no significant association between total APACHE II score and its calculated mortality and different motoric subtypes; however, they were higher in hypoactive delirium mostly due to small number. O'Keefe and Lavan (29) prospectively examined hospital patients and reported that a higher percentage of hypoactive $(21 \%)$ patients died compared to hyperactive $(15 \%)$, mixed $(16 \%)$, and neither (0\%). Camus and colleagues (30) compared the etiologic and outcome profiles in a case series of 183 elderly patients and found that hypoactive patients had the highest mortality $(10 \%)$ followed by hyperactive $(9 \%)$ and mixed $(6 \%)$. The findings of these two studies were consistent with the results of the current study.

Marcantonio and colleagues (31) prospectively studied hip fracture surgery patients and found that hyperactive patients (including mixed-type patients who were combined with the hyperactive types) were more likely to die after hip fracture compared to hypoactive patients, though this difference was not statistically significant. Moreover, Kelly and colleagues (32) studied a series of nursing facility delirious patients and reported that psychomotor activity delirium subtype did not predict mortality during or subsequent to the patient's hospitalization. However, they reported that hypoactive patients were more likely to have persistent delirium and that patients with persistent delirium were more likely to die in the hospital compared with patients who resolved their delirium. Our study significantly added to the above literature by examining different etiologies and elderly who were living at their homes.

There was no significant difference between types of delirium as regard depression and dependence in performing ADL or IADL. Yet, the hypoactive delirious patients had a higher depression score and were more dependent functionally at baseline. This may indicate the association of poorer baseline functional state and the worse general premorbid condition with hypoactive delirium.

\section{Conclusion}

Our findings have substantial clinical significance. The hypoactive form of delirium was common among older persons. The hypoactive form of delirium had significantly higher ESR in comparison with hyperactive subtype. Hypoglycemia was significantly the most frequent cause of hypoactive type while dehydration was significantly the most frequent reason among mixed type. Hypoactive type patients are not immediately disruptive to their medical care, yet their delirium makes them unlikely to engage in activities that will promote recovery from acute illness. This finding has additional importance considering that hypoactive subtype of delirium often goes unrecognized, it is recommended to promptly recognize hypoactive delirium and to put a proper plan for ADL support and functional rehabilitation.

\section{References}

1. Thomas RI, Cameron DJ, Fahs MC: A prospective study of delirium and prolonged hospital stay. Arch Gen Psychiatry 1988; 45:937-940.

2. Rabins PV, Folstein MF: Delirium and dementia: diagnostic criteria and fatality rates. Br J Psychiatry 1982; 140:149-153.

3. Lipowski ZJ. Transient cognitive disorders (delirium, acute confusional states) in the elderly. Am J Psychiatry 1983; 140:1426-1436.

4. Liptzin B, Levkoff SE. An empirical study of delirium subtypes. $\mathrm{Br} \mathrm{J}$ Psychiatry. 1992;161: 843-845.

5. Meagher DJ, Hanlon DO, Mahony EO et al. Relationship between symptoms and motoric subtype of delirium. J Neuropsychiatry Clin Neurosci 2000;12: 51-56

6. Fong TG, Tulebaev, and Inouye SK. Delirium in elderly adults: diagnosis, prevention and treatment. Nat Rev Neurol. 2009; 5(4): 210 220.

7. Lipowski ZJ. Delirium in the elderly patient. N Engl J Med 1989;320: 578-582.

8. American Psychiatric Association. Practice guideline for the treatment of patients with delirium. Am J Psychiatry 1999;156: 1-20.

9. Inouye SK, Bogardus ST Jr, Charpentier PA et al. A multicomponent intervention to prevent delirium in hospitalized older patients. N Engl J Med 1999:340: 669-676.

10. Deyo RA, Cherkin DC, Ciol MA. Adapting a clinical comorbidity index for use with ICD-9-CM administrative databases. J Clin Epidemiol 1992;45: 613-619.

11. Inouye SK, van Dyck CH, Alessi CA, Balkin S, Siegal AP, Horwitz RI. Clarifying confusion: the confusion assessment method. A new method for detection of delirium. Ann Intern Med.1990;113:941-948.

12. Liptzin B, Levkoff SE: An empirical study of delirium subtypes. $\mathrm{Br} \mathrm{J}$ Psychiatry 1992; 161:843-845.

13. Alexopoulos GS, Abrams RC, Young RC, Shamoian CA. Cornell Scale For Depression in Dementia. Biological Psychiatry 1988;23:271-84.

14. Katz, S., Ford, A. B., Moskowitz, R. W., Jackson, B. A., \& Jaffe M. W. Studies of illness in the aged: The index of ADL: A standardized measure of biological and psychosocial function. JAMA, 1963:. 185(12), 94-99.

15. McDowell I, Newell C Physical disability and handicap. In: McDowell I, Newell C (eds), Measuring health: a guide to rating scales and questionnaires. 2nd edn. New York, Oxford University Press, 1996:. 47121.

16. Kovar MG, Lawton MP Functional disability: activities and instrumental activities of daily living. Ann Rev Gerontol Geriatr 1994;. 14:57-75.

17. Morandi A, Jackson J.C and Ely E.W. Delirium in the intensive care unit. International Review of Psychiatry. 2009;21(1):43-58.

18. Peterson J.F, Pun BT, Dittus R.S, Thomason J.W, Jackson J.C, Shintani A.K and Ely EW. :Delirium and its motoric subtypes: a study of 614 critically ill patients. J Am Geriatr Soc .;2006; 54(3):479-484.

19. Robinson T.N, Raeburn C.D, Tran Z.V, Brenner L.A and Moss M. Motor subtypes of postoperative delirium in older adults. Arch Surg 2011.;146(3):295-300.

20. Mushtaq R, Shoib S, Shah T, Dar M and Mushtaq S. Recognizing Changes in Cognition in Sub Types of Acute Confusional State. Journal of Clinical and Diagnostic Research.2014; 8(7): 1-3.

21. Grover S, Sharma A, Aggarwal M, Mattoo S.K, Chakrabarti S, Malhotra S, Avasthi A, Kulhara $P$, and Basu D. Comparison of symptoms of delirium across various motoric subtypes. Psychiatry and Clinical Neurosciences. 2014; 68: 283-291.

22. Aly W.W, Abdul-Rahman S.A, EI Said S.M and Bastawy S.A S100B and delirium in the geriatric acute care setting. Advances in Aging Research.2013.;3(1)1-5.

23. Angles E.M, Robinson T.N, Biffl W.L, Johnson J, Moss M, Tran Z.V and Moore E.E.:Risk factors for delirium after major trauma. Am J Surg. 2008.; 196(6):864-869.

24. Meagher D.J, MacLullich A.M and. Laurila J.V. Defining delirium for the International Classification of Diseases, 11th Revision," Journal of Psychosomatic Research. 2008; 65 (3) :207-214.

25. Solai LKK. Delirium. In: Saddock BJ, Saddock VA, Ruiz P, editors.( Comprehensive textbook of psychiatry. Baltimore: Lippincott Williams and Wilkins. 2009; 1153-1167.

26. Meagher D.J, Moran M, Raju B, Gibbons D, Donnelly S, Saunders J and Trzepacz PT. Phenomenology of delirium. Assessment of 100 adult cases using standardised measures. Br J Psychiatry.2007.;190: 41-135.

27. Stagno D, Gibson $C$ and Breitbart W. (The delirium subtypes: a review of prevalence, phenomenology, pathophysiology, and treatment response. Palliat Support Care. 2004;2: 9 -171. 
Hamza SA et al. EJGG.2015; 2(2):12-17

28. Khurana V, Gambhir I.S, and Kishore D.( Evaluation of delirium in elderly: a hospital-based study. Geriatrics and Gerontology Internationa.2011: 11(4):467-473.

29. O'Keeffe ST, Lavan JN. Clinical significance of delirium subtypes in older people. Age Ageing.1999:28:115-119.

30. Camus V, Gonthier R, Dubos G, Schwed P, Simeone I. Etiologic and outcome profiles in hypoactive and hyperactive subtypes of delirium. J Geriatr Psychiatry Neurol.2000;13:38-42.

31. Marcantonio E, Ta T, Duthie E, Resnick NM. Delirium severity and psychomotor types: their relationship with outcomes after hip fracture repair. J Am Geriatr Soc. 2002;50:850-857.

32. Kelly KG, Zisselman M, Cutillo-Schmitter T, Reichard R, Payne D, Denman SJ. Severity and course of delirium in medically hospitalized nursing facility residents. Am J Geriatr Psychiatry.2001;9:72-77. 